\title{
MANIFESTAÇÕES CULTURAIS E CORPÓREAS DO ENFERMEIRO NA SUA
} PRÁTICA GERENCIAL

CULTURE AND CORPORAL MANIFESTATIONS OF THE NURSE IN HIS/HER MANAGERIAL

\author{
PRACTICE \\ LAS MANIFESTACIONES CORPORALES Y CULTURALES DEL ENFERMERO EN SU PRÁCTICA \\ ADMINISTRATIVA
}

\author{
Adelina Giacomelli Prochnow', Josete Luzia Leite', Maria Auxiliadora Trevizan ${ }^{3}$
}

\begin{abstract}
${ }^{1}$ Enfermeira. Doutora em Enfermagem pela Escola de Enfermagem Anna Nery (EEAN) da Universidade Federal do Rio de Janeiro (UFRJ). Professora Adjunto da Universidade Federal de Santa Maria (UFSM), Santa Maria, RS. Membro do Núcleo de Pesquisa Educação, Gerência, Exercício Profissional (NUPEGEPEn) da EEAN/UFRJ.

2 Enfermeira aposentada. Professora titular Emérita Universidade do Rio de Janeiro (UNIRIO). Membro da Diretoria do NUPEGEPEn. Pesquisadora 1A do Conselho Nacional de Desenvolvimento Científico e tecnológico (CNPq).

${ }^{3}$ Enfermeira. Professora Titular da Escola de Enfermagem de Ribeirão Preto (EERP) da Universidade de São Paulo (USP), Centro Colaborador da Organização Mundial de Saúde (OMS) para o Desenvolvimento da Pesquisa em Enfermagem. Pesquisadora 1A do CNPq. Líder do Grupo de Pesquisas sobre Utilização de Recursos Humanos em Enfermagem (GEPURHEn).
\end{abstract}

PALAVRAS-CHAVE: Enfer- RESUMO: Este estudo teve como objetivo denotar especificidades gerenciais, analisadas segundo a magem. Gerência. Cultura.

Teoria Interpretativa da Cultura, que se expressam como manifestações culturais no âmbito da gerência do enfermeiro em um Hospital Universitário. Trata-se de um estudo descritivo de caráter qualitativo e interpretativo de entrevistas de vinte e dois enfermeiros no exercício gerencial. As manifestações corpóreas do enfermeiro gerente emergem como expressões culturais do ser humano como ser gerente em sinergia com vários elementos fruto de um corpo que se emociona no exercício da gerência. Contribui para o avanço no conhecimento e capacidade de enfrentamento das incertezas nos espaços organizacionais, na complexidade do ambiente hospitalar.

KEYWORDS: Nursing. Management. Culture.

PALABRAS CLAVE: Enfermería. Gerencia. Cultura.

\begin{abstract}
The objective of this study is to denote managerial specificities, analyzed according to the Culture Interpretative Theory. These specificities are expressed as cultural and corporal manifestations in the scope of the nursing management in a University Hospital. It is a descriptive study of qualitative and interpretative character, having interviewed twenty two nurses in their management functions. The corporal manifestations of the managing nurse arise as culture manifestations of the human being as a manager and a body in synergy with many elements as a result of a body that gets excited or feels emotion when managing. This study contributes to the advance of knowledge and to the capacity of confronting organizational uncertainties, within the complexity of the hospital environment.
\end{abstract}

RESUMEN: Este estudio tuvo como objetivo denotar las especificidades administrativas, analizadas según la Teoría Interpretativa de la Cultura, que se expresan como las manifestaciones culturales en el ámbito de la gerencia del enfermero en un Hospital Universitario. Se trata de un estudio interpretativo de naturaleza cualitativa a través de entrevistas a veintidos enfermeros durante el ejerciciode de la gerencia. Las manifestaciones corporales del enfermero administrados aparecem como expresiones culturales del ser humano en cuanto ser gerente en sinergía con los diferentes elemento como fruto de un cuerpo que se emociona con el ejercicio de la administración. Contribuye para el progreso en el conocimiento y la capacidad de confrontación de las incertidumbres en los espacios organizacionales, así como en la complejidad del ambiente hospitalario.
Endereço: Adelina Giacomelli Prochnow

R. Franklin Bittencourt Filho, 65

97.105-150 - Camobi, Santa Maria, RS.
Artigo original: Pesquisa

Recebido em: 14 de fevereiro de 2006.

Aprovação final: 27 de junho de 2006.

Texto Contexto Enferm, Florianópolis, 2006 Jul-Set; 15(3): 449-57. 


\section{INTRODUÇÃO}

Trata-se de um estudo cujo recorte é a tese de doutorado intitulada "O Exercício da gerência do Enfermeiro: cultura e perspectivas interpretativas". ${ }^{1}$ Essa investigação surgiu a partir da trajetória do nosso exercício profissional, no contexto hospitalar, e das dificuldades que vêm emergindo da tarefa de administrar, visto que nosso saber-fazer está imerso em contradições vinculadas às raízes da profissão e interrelacionadas à racionalidade instrumental e econômica, o que culmina em perplexidade, diante de situações naturalizadas ante o complexo relacionamento com a estrutura social em seu conjunto.

O hospital, classificado como organização complexa do sistema de cuidado à saúde, denota o poder normativo como fonte de controle dos participantes dos níveis inferiores do sistema, no qual se apóia para a internalização das diretrizes aceitas como legítimas caracterizadas pelo alto engajamento. ${ }^{2}$ Dessa forma, vivenciamos premências na resolução de problemas de relacionamento humano; urgência na aquisição de materiais essenciais para execução das tarefas do diaa-dia; e, ainda, incongruências do tempo disponível para execução do trabalho associado à produção de conhecimento, entre outros problemas.

Aliado a isso, o aumento constante da complexidade da instituição, as inovações tecnológicas, a explosão de mudanças mercadológicas, a subdivisão das atividades administrativas e dos cuidados (assistenciais) acentuam alguns dilemas enfrentados no cotidiano do enfermeiro gerente, referentes à escolha de alternativas para a tomada de decisões, a fim de serem executadas as mudanças exigidas pelo mercado de trabalho.

A maneira de administrar permanece, na Instituição em estudo, dominada pela racionalidade instrumental, destacando o taylorismo sob o ponto de vista da produção, da organização do trabalho e da gerência. Tal sistema salienta o excessivo aproveitamento do tempo e dos movimentos no processo de trabalho e o uso exagerado da padronização da produção, da tecnologia e do processo de trabalho por categorias econômicas, rigidamente estabelecidas, o que torna o cotidiano exaustivo e exacerba os conflitos a serem enfrentados no diaa-dia da prática gerencial do enfermeiro.

A administração, nesse exercício de trabalho contrário à idealização que vislumbramos na formação profissional e à inserção no mercado de trabalho, faz com que nos deparemos com o mundo dos negócios, no qual percebemos, por meio do sofrimento, do desconforto existencial, da violência psicológi- ca, da nostalgia, do desespero, a sensação de impotência e ineficácia no trabalho, como reflexo da formação e da imagem geralmente recebida e cultivada pela sociedade global.

Nessa linha de pensar, o presente estudo tem como objetivo denotar especificidades gerenciais, analisadas segundo a Teoria Interpretativa da Cultura, que se expressam como manifestações culturais e corpóreas no âmbito da prática profissional do enfermeiro em um Hospital Universitário. Pretende-se com o mesmo, possibilitar o aprimoramento de nossos conhecimentos e capacidades de enfrentamento diante das incertezas laborais inerentes à complexidade do atual ambiente hospitalar.

\section{BREVE FUNDAMENTAÇÃO TEÓRICA}

Para compreender a realidade cultural dentro de um contexto hospitalar singular, de significados sociais complexos, buscamos sustentação teórica na Antropologia Interpretativa ${ }^{3-7}$. Além disso, utilizamos alguns parâmetros norteadores complementares, relacionados à configuração do estudo no que tange ao trabalho no Brasil e ao processo gerencial do enfermeiro.

A interrogação do homem sobre si mesmo, sobre a sociedade, sobre seu saber é tão antiga quanto a humanidade, porém o homem como objeto de conhecimento da Antropologia, constitui um saber pretensamente científico somente no fim do século XVIII e adquire legitimidade como ciência a partir da segunda metade do século XIX. Com a evolução social no início do século XX, a Antropologia encontra-se em uma crise de identidade e elabora seus próprios métodos de pesquisa, iniciando a antropologia moderna. ${ }^{8}$

Nesse processo, a teoria de Interpretativa da Cultura sustenta-se nos parâmetros humanísticos, interpretativos, embasados na hermenêutica, na crença de que os textos ou produção intelectual são construções fundamentadas em uma atmosfera de diversidade, pluralismo e conflito, o que é intelectualmente vital para uma disciplina. ${ }^{4}$

Por essa concepção, o conhecimento antropológico surge das práticas simbólicas e dos discursos embasados nas diferenças e suas fronteiras. Assim, a busca do conhecimento pela antropologia interpretativa ocorre pelo esforço de entender o outro, o diferente, que leva as pessoas a verem-se como os outros as vêem. Para utilizar a ciência social interpretativa, em geral, é importante estar ciente de que as incertezas e as ambigüidades fazem parte do processo de forma intensa, pois trocam as relações causais, cíclicas, por 
uma gama de tentativas de explicação, em um contexto particular, no qual surgirão inúmeras dificuldades desconhecidas.

Assim, a antropologia interpretativa baseia-se na interpretação das experiências e na utilização dos "relatos daquelas interpretações para tirar algumas conclusões sobre expressão, poder, identidade, ou justiça, sentimo-nos, a cada passo, bem distantes de estilospadrão de demonstração. Utilizamos desvios, encontramos por ruas paralelas (...)" 5:14 Dessa forma, seu trabalho analisa os entendimentos diferentes dos já estabelecidos culturalmente. Tais compreensões o autor denomina hermenêutica que, adicionada da palavra cultural, define o que ele faz.

Em face disso, cultura é "uma ciência interpretativa, à procura do significado". O significado é construído e estabelecido socialmente, sendo "essencialmente semiótico"; portanto, surge de um contexto com sistemas entrelaçados de símbolos públicos interpretáveis. ${ }^{6: 4}$ Como a análise da cultura transpõe o próprio corpo do objeto, ela conduz o pesquisador a iniciá-la com interpretações sobre o que se imagina que pretendem os informantes para após sistematizá-las como um fato natural.

A gerência do cuidado de enfermagem, por sua vez, pode ser vista por diferentes olhares o que permite visualizar a sua unidade na totalidade e as suas várias dimensões e facetas, orientadas pelos sistemas simbólicos representativos das composições organizacionais dos serviços de saúde, cuja noção de pluralismo possibilita a identificação das diferentes facetas dessa arena social. ${ }^{9}$

A prática gerencial do enfermeiro representa unidades de pensamento, ou os símbolos interligados dentro das relações de significado que estruturam a dinâmica do trabalho realizado pelos profissionais de enfermagem, caracterizando uma cultura própria.

Nesse cenário, o exercício da gerência como liderança de enfermagem é vislumbrada "pelo modo de expressão do potencial de ser humano no exercício das relações participativas e interativas e na construção de novos saberes e práticas integrativas compartilhadas, que possibilitem a criação e recriação de valores que os tornam sujeitos críticos, reflexivos e transformadores da realidade social". 10:146

A cultura é "um conjunto de mecanismos de controle - planos, receitas, regras, instruções (o que os engenheiros de computação chamam de "programas") - para governar o comportamento". 3:56 O mesmo autor complementa que o ser humano é, desespera- damente, dependente de tais programas culturais e de mecanismos de controle extra genéticos, para ordenar seu comportamento.

\section{METODOLOGIA}

Trata-se de uma pesquisa descritiva de caráter qualitativo, na qual utilizamos o discurso dos entrevistados e as observações realizadas no transcorrer da pesquisa como fonte de informação para a análise das manifestações culturais e corpóreas do enfermeiro no seu exercício gerencial.

Depreendendo que o material com o qual trabalhamos fundamenta-se a partir do diálogo interativo desenvolvido através de entrevistas e da análise das mesmas, partindo da premissa de que tudo que é dito é passível de ser submetido à análise e interpretação, norteamos o estudo a partir do enfoque de cultura como às teias de significado que o ser humano teceu e nas quais ele se encontra e enxerga seu mundo, sempre procurando seu significado, ${ }^{4}$ com isso objetivamos a compreensão do objeto de estudo.

Para tanto, a pesquisa foi desenvolvida em um Hospital Universitário do Estado do Rio Grande do Sul, certificado como de Ensino e caracterizado como de Porte IV, mediante comunicação prévia e devida autorização, seguindo os preceitos éticos para pesquisa que envolve seres humanos, conforme estabelece a Resolução 196/96, e aprovação do Comitê de Ética da referida instituição. ${ }^{11}$

As situações que emergiram de nossas observações foram incorporados aos relatos do grupo a fim de, posteriormente, serem associados a prerrogativas teóricas. Para isso, foi necessário flexibilidade, pois, em qualquer momento do estudo, é possível o encontro com descobertas inesperadas, o que exige uma reorientação dos caminhos durante seu desenvolvimento, forçando-nos a inter-relacionar os diversos fenômenos específicos da pesquisa.

Para a organização do pensamento interpretativo utilizamos na pesquisa a perspectiva dedutiva, indutiva e perceptiva. Esses aspectos têm em vista possibilitar o emergir compreensivo, através da articulação da teoria e prática, que se estabelece na dinâmica entre sujeito e objeto segundo a ótica dos pesquisados e do caminho interpretativo do pesquisador.

Compuseram o estudo vinte e dois enfermeiros chefes de unidades de enfermagem, no período de abril a setembro do ano de 2003, os quais foram selecionados de forma intencional em virtude do cargo por eles exercido no período em que se desenvolveu a pesquisa.

Texto Contexto Enferm, Florianópolis, 2006 Jul-Set; 15(3): 449-57. 
A coleta de dados foi realizada mediante a técnica de entrevista individual, tendo como instrumento um roteiro de temas referentes ao cotidiano gerencial do enfermeiro, no que tange as condições de trabalho, hábitos, desempenhos, enfrentamentos, percepções, regras, normas sistemáticas, crenças, tomada de decisões, e outros, com a finalidade de denotar especificidades gerenciais que pudessem ser compreendidas como conflitos no âmbito da prática profissional e as manifestações culturais e corpóreas do enfermeiro nessa atividade. Os dados coletados foram gravados e transcritos na íntegra sendo posteriormente validados pelos partícipes. No texto, os depoentes, estão identificados com a letra " $D$ ", seguida dos números de 1 a 22, correspondentes aos depoimentos realizados.

O processo analítico envolveu leituras e averiguações dos dados relevantes para interpretar o fenômeno em voga, seguindo as etapas a fim de "penetrar no próprio corpo do estudo" "4:11 que, foram assim desenvolvidas: primeira etapa, momento de desconstrução ou desmontagem de documentos a fim de traçar a curva do discurso social, interrogações, verificação dos processos naturais duradouros e grau de variação de significado, evidências subjetivantes, reconstrução da realidade, ou seja, enxergar o significado das coisas a partir das determinações e especificidades estabelecidas pelo grupo social em si; segunda etapa, interpretação, momento em que procurou-se sistematizar e descrever um significado mais abrangente dos dados, vinculando-os a outros conhecimentos, a partir da seleção e destaque dos elementoschave de significado, percepção dos sentidos nos enunciados especificando as relações internas entre os elementos que caracterizam e descrevem o dito" no discurso social, a fim de tornar explícito o conhecimento implícito; e, terceira etapa, evidência e descrição do que o ato simbólico tem a dizer sobre ele mesmo.

\section{APRESENTAÇÃO E DISCUSSÃO DOS RESULTADOS}

As manifestações culturais do enfermeiro gerente apresentam questões que emergem como manifestações corporais do ser humano, porque evidenciamos que cultura, gerência e manifestação corporal atuam de forma sinérgica. A gerência não é uma função isolada, é realizada pelo homem enquanto sujeito social; pois, possui normas, teorias e modelos em que cada corpo se utiliza daquele saber, conhecimento advindo de uma educação, de uma trajetória de vida, em um espaço determinado, situando uma cultura gerencial singular é, portanto, dessas manifestações que dissertamos neste artigo.

O corpo, "é pensado, representado e passível de leituras diferenciadas de acordo com o contexto social [...]. O corpo é reflexo da sociedade, não sendo possível conceber processos exclusivamente biológicos, instrumentais e estéticos no comportamento humano. Ao corpo se aplicam sentimentos, discursos e práticas que estão na base de nossa vida social. Por sua vez, o corpo é emblemático de processos sociais". ${ }^{12: 101}$

Observamos, nessas manifestações, vários elementos em um corpo que se emociona no desenvolvimento do exercício da gerência do enfermeiro. Encontramos alguns elementos relevantes e destacamos para análise.

Considerando o corpo como signo, passa-se a integrar o processo de comunicação, visto que transmite informações, desde que percebido e compartilhado pelo grupo social. ${ }^{12}$ De acordo com a historicidade de cada sujeito, as sensações corporais se diferenciam e são sentidas e expressas por meio de códigos específicos. Portanto, as leituras desses símbolos estão na dependência do pensar, exprimir e identificar estas mensagens ligadas à representação de trabalho, gerência, profissão, saúde/doença, vigente no grupo de trabalho da instituição.

Nesse âmbito, a Enfermagem tem uma pluralidade de signos que apresentam distintas visões de mundo e expressam aos seus integrantes posições ou papéis específicos no contexto hospitalar. O corpo "pode ser tomado como um suporte de signos, ou seja, suporte de qualquer fenômeno gerador de significação e sentido". 12:102 Signo é "algo que existe por outra coisa diferente, que indica algo diverso de si mesmo". ${ }^{13: 141}$ Assim, podemos inferir que a linguagem é um sistema de signos compartilhados destinados à comunicação, freqüentemente expressos pelo corpo.

Expor manifestações como uma realidade culturalmente construída significa investigar o exercício da gerência sob a perspectiva dos seus atores, incluindo intenções e encaminhamentos com diretrizes coletivas.

Através das falas dos entrevistados, percebe-se a incorporação de elementos ideológicos que mani- 
festam sua origem na forma de organização do trabalho, e reportam a idéia de lealdade às instituições, de talento, de reconhecimento, de valores relacionados à questão moral como: responsabilidade, disciplina, engajamento, harmonia, comprometimento, valorização do ser humano, que resultam em um sentimento que demonstra afinco com o caráter religioso e militar, o que justapõe alguns mitos, que servem de base à sua prática, experiência ou para re-orientar as ações em função dos novos contextos construídos. ${ }^{14}$

Nas falas, por exemplo, os enfermeiros referem que, quando fazem críticas, chamam a pessoa para um ambiente mais reservado, como uma sala no mesmo andar, ou mesmo na sala de lanche. Se acontecer no momento do trabalho, marcam em um local mais isolado, de forma que a conversa possa ser individual. Eles narraram que se preparam psicologicamente para as argumentações, demarcam um caminho antes de expor a situação objetiva do encontro, preservam o envolvido e, também pedem proteção a Deus. Os depoentes expressam-se em linguagem direta e não separam elogios de repreensões. Buscamos situar esse emaranhado de procedimentos entre as percepções construídas pelos enfermeiros gerentes, relacionandoos às redes estruturais que organizam e interferem em sua prática gerencial.

Importante ressaltar que o processo de comunicação é formulado de maneira que se possa persuadir o outro. A manipulação que, acreditamos, pode ser traduzida como assédio moral, é utilizada como uma técnica de exercício de poder, visando ao adestramento do outro, forjando, de maneira coercitiva, a mobilidade ou a expressão do mesmo.

Em relação à visão e às influências que caracterizam suas concepções, destacam-se as seguintes falas: com certeza, háinfluência da trajetória de vida, eu passeisempre em colégios com freiras. Sem sombra de dúvida, atéas pessoas me acham com cara de freira (D19); da minha trajetória de vida, da minha religiosidade, daeducaşão, tem tudo avercom a questãoespiritual. Formação acadêmica influenciouno conbecimento básico(D9).

Os relatos apresentados revelam que há uma associação da trajetória de vida, educação familiar, experiências de casa, formação acadêmica; tudo consta da experiência pessoal e profissional e se manifestam no comportamento. Os enfermeiros demonstram a influência da religiosidade, expressa, com maior ênfase, pelos que efetivaram seus estudos em escolas coordenadas por irmandades.

As forças que regulam as lutas públicas salien- tam que "uma das energias centrais que impulsionam essas lutas: o sentimento de quem são aqueles de quem se descende, quem são aqueles com quem se é parecido no pensar, na aparência, na maneira de falar, de comer, de rezar ou nos gestos e a quem, por conseguinte, sente-se que se está empaticamente ligado, haja o que houver"..$^{6207}$

Além do conhecimento técnico aprendido na academia, é relevante a percepção da proveniência e influência da ordenação existente de valor, expressões e ideologia, no caráter das pessoas nos seus enredos cotidianos.

Quanto ao relacionamento com a equipe de trabalho, os depoentes expressam que: tem momentos de confitos, massãopoucos, nãosão muitos. Nogeral, estámelhorando bastante, agenteestáconseguindo interagir, trabalhar bem(D)); ébomo relacionamento, tem algumas dificuldades, massão coisas quesemprevaiter, quetá dentro da normalidade(D9).

Os sujeitos incluem, no relacionamento, algumas dificuldades que consideram inerentes ao processo de trabalho. Salientam que, diante da importância do relacionamento interpessoal, no dia-a-dia há uma considerável melhoria da convivência; porquanto, respeitase o domínio privado do outro, mas não se respeita o próprio indivíduo em si.

É possível dizer que se torna evidente que as relações são de aparência, moldadas e modeladas conforme regras não reguladas por normas formais, porém distintas de acordo com as posições e atribuições hierárquicas. Exemplificamos: eu procuro aqui ser estritamenteprofissional, nãoquero muitorelacionamento. Geralmente sou muito seca. É muito profissional, não quero saber de encosto para meu lado, éprofissional e caio fora(D19).

Apenas um dos informantes declarou manter um relacionamento estritamente profissional, sendo direto e tratando somente de assuntos profissionais no trabalho, sem contornos, manifestações diversificadas, ou alternativas para chegar ao assunto, diz ser prático e de poucas palavras.

Nessa lógica, pôde-se constatar que a distância afetiva expressa representa uma forma de não se comprometer com o outro, pois "na lógica perversa, não há a menor noção de respeito pelo outro. A sedução perversa não comporta a menor afetividade, pois o princípio do funcionamento perverso é evitar qualquer afeto. Os perversos não se interessam pelas emoções complexas dos outros. São impermeáveis ao outro e à sua diferença, a não ser quando têm a impressão de que essa diferença pode atrapalhá-los. É uma negação total da identidade do outro, cujas atitudes e pen-

Texto Contexto Enferm, Florianópolis, 2006 Jul-Set; 15(3): 449-57. 
samentos devem estar de acordo com a imagem que eles próprios têm do mundo". ${ }^{15: 145}$

Os depoentes revelaram que adotam um comportamento manifesto para evitar atritos, ou seja, evitar situações conflitantes. Dessa forma, a maioria deles afirma não gostar de chamar a atenção das pessoas, nem repreendê-las pelos seus atos. Porém, quando o conflito torna-se inevitável, os participantes da pesquisa tendem ao diálogo individual, na tentativa de evitar constrangimentos no coletivo. Além disso, eles buscam, normalmente, ouvir as partes, escutando-as para, após, conversarem. Assim, eles evitam expressar limitações, em momentos coletivos, somente em situações inusitadas, ou que envolvam o grupo. Vejamos os seguintes trechos dos depoimentos coletados: proponho ir direto com a pessoa, se não dá, en converso como responsável do serviço ou chefe da disciplina(D5); abertura para umaboa conversa, chama, endou um cafezinho para agradar, coloco tudo o que estava acontecendo, essas dificuldadese, dai, conversandoacabadiminuindo o conflito(D14); a reunião mensal ésistemática, então, a gente fala ali na reunião pra todo mundo, secolocasituaçóese a pessoa que vivenciou sabe, então, as vezes, sóalijá melhora (D9).

Importante ressaltar que houve manifestações expressas, nas quais os depoentes, mesmo quando seguros da situação e sentindo-se tranqüilos, não consideram fácil enfrentar situações de repreensão e advertências. Outra depoente mencionou o enfrentamento de problemas como um exercício, no qual ela estabelece uma linha de atuação, que quando seguida, segundo ela, impede que alguns acontecimentos a atinjam.

O hábito de chamar a atenção em particular nos reporta aos paradoxos que permeiam as relações entre chefe e subordinado, nas quais percebemos que eles apelam às hierarquias freqüentemente. Dessa for$\mathrm{ma}$, acreditamos que as ações recorrem às diferenças e podem pretender exaltar a simetria. Para tanto, fica manifesto o fato de existir um espaço em que se expressa o ideal pela democracia, igualdade. No entanto, a negociação, a portas fechadas, pode demonstrar, no mínimo, a facilidade em ditar normas e regras. $\mathrm{O}$ uso da autoridade, em contrapartida, pode demonstrar a dificuldade em seguí-las e flexibilizá-las sempre que necessário, representar uma forma de proteção ao acometido, ou ainda uma forma obscura de negação do conflito, na qual a vítima não pode se defender e permanece, então, paralisada.

Quanto ao hábito de expressar elogios ou falar das limitações no relacionamento com as equipes, os depoentes contam que, normalmente, elogiam em público, aproveitam as reuniões, ou o dia-a-dia, sem muitos adereços, já que é um processo mais fácil do que encarar problemas. Convém lembrar, no entanto, que vários depoentes demonstraram limitações, das quais salientaram que faz parte das obrigações fazer o trabalho bem feito, pois o negativo sempre aparece mais. Observam que utilizam os elogios como estratégia para a motivação, assim, fica o exemplo para que outros possam seguir.

Nesse contexto, a comunicação apresentou-se de maneira paradoxal, pois entre os membros da equipe notamos uma abertura ao diálogo e a uma conversa mais direta. Entretanto, quando a utilizam para repassar e alertar para o cumprimento de ordens advindas da hierarquia, percebemos que a mesma se torna perversa.

Por essa via de reflexão, nas falas dos informantes surge como destaque, o uso de expressões divinas e de ditados religiosos, como um hábito ante as dificuldades, como um alento, desabafo ou como uma procura de forças para a continuidade e a superação dos enfrentamentos.

Deusdo céu![...] acho que a enfermeiraé, nós somos os anjos da guarda (D22).

Ih, meu Deus! Pelo amorde Deus! Deus ajude! (D10).

Maldade. Se um dia en fizer, eu pago. E a gentepaga podetercerteza. Euacredito assim, muito nisso(D14).

Tais falas servem de guia para a manutenção da busca dos ideais e dos valores nas diferentes circunstâncias, o que nos leva à compreensão de que a fé religiosa age sobre a vida moral. Nesse sentido, tais atos buscam atingir consciências, ultrapassando o mundo material.

Imbricados nos acontecimentos, começamos, então, a nos interrogar: Estão aí os rituais do comprometimento árduo? Da exigência máxima consigo mesmo? Da necessidade de controle, de regras, de normas, enfim de sistematizações? Da subordinação? Do extremo valor ao ser humano? De manter os enfermeiros em conflito com os seus valores e padrões estabelecidos? Seria um dos motivos de busca de formulações dogmáticas e divinas? É um recurso para suportarem situações difíceis, como os impasses advindos do cotidiano laboral?

Pode-se inferir que as concepções religiosas expressas pelos depoentes, parecem desempenhar um papel controlador, dominador e manipulador, visto que eles prescrevem uma moral pública a si e aos seus companheiros de trabalho. ${ }^{6}$ Portanto, o sentido expresso na religiosidade, ligado aos afetos do coração, declarado de maneira subjetiva, vincula a moral como força social. Eles se resignam a ela como o preço ne- 
cessário a ser pago pelas coisas boas, pelo progresso, pela paz, pela liberdade de consciência.

As falas expõem um repertório básico de ações especiais que são partilhadas entre os enfermeiros, diante de diferentes fatos (cotidianos e não cotidianos), que demonstram uma perpetuação de seqüências estabelecidas, padronizadas e expressas por atos e palavras, com o intuito de resolver conflitos, diminuir incompatibilidades e, ao mesmo tempo, transmitir conhecimentos socialmente adquiridos e aceitos pelo grupo.

Nos relatos, o foco recai na forma de comunicação deles diante de conflitos, pois "[...] os contemporâneos são pessoas que partilham uma comunidade no tempo, mas não no espaço: eles vivem (mais ou menos) no mesmo período da história e muitas vezes mantém relações sociais muito tênues entre si, porém não se encontram - pelo menos no curso normal das coisas. Eles se ligam não através de uma interação social direta, mas através de um conjunto generalizado de pressupostos formulados simbolicamente (isto é, culturalmente) sobre os modos típicos de comportamento um do outro" $4: 152$

$\mathrm{Na}$ vida, a pessoa conjuga um todo, de forma que ao ser fragmentado, ela reage por meio de comportamentos específicos, a partir da socialização expressa no domínio da experiência cotidiana de cada pessoa. Como resultado surgem reações corpóreas expressas através de emoções.

Quanto aos enfrentamentos cotidianos, os depoimentos expressaram emoções que afloram e são entendidas como dependentes da situação, todavia são sempre negativas como: tensão nervosa, mágoa, desvalorização, desconforto, desgaste, angústia, frustração, preocupação, estresse, incômodo, cansaço, impotência, brabeza, raiva e indignação, sensação ruim. Inclusive houve manifestações físicas de insônia e hipertensão arterial.

[...] como outro. Eu tenho isso, procuro não ter aproximaçãocomninguém, não visitoninguém, ninguém freqüentaminha casa (D 19).

Nesse sentido, o enfermeiro mantém sua postura marcada pelo obscurantismo nas relações, colocando-se aprioristicamente sob um estado de vigília perante os possíveis esclarecimentos e embates, no decorrer dos encontros. Tal postura pode denunciar uma forma de proteção ou defesa, haja vista a fragilidade denotada referente ao envolvimento pessoal, nas relações. Esse profissional permanece vinculado a um tipo mental idealizado de comportamento, concebido e incorporado como típico em circunstâncias específicas.

Assim, os entrevistados demonstram comprometimento, empenham-se muito para o exercício do cargo, vêem-se com pouca resolutividade devido tanto aos entraves do serviço público quanto ao sistema capitalista, no qual as resoluções não dependem só deles.

Com referência às imposições de decisões praticadas pela organização institucional, no trabalho cotidiano, as opiniões emanadas foram ambivalentes. Ao falarem dos próprios sentimentos que eclodem quando há imposição, emergiram as emoções, tais como: raiva, hostilidade, frustração, preocupação, desgosto, descrédito, indignação. Alguns depoimentos consideram a instituição democrática; outros, como uma instituição que tem uma organização vertical de trabalho, as resoluções são impostas, de cima para baixo.

Preocupação. Como isso vai refletirno grupo, tem essa preocupação de insegurançatalveze como ogrupo vai reagir (D 12).

Frustração impotência, émais uma coisa que não vai adiante (D 15).

Assim, os depoentes acreditam que devem se isentar de emitir juízo de valor e apenas repassar as ordens da forma mais técnica possível, já que certas decisões não dependem deles. Eles preferem não discutir a estrutura e cumprir o imposto, pois deve ser assim e não adianta.

Tem-se uma direção, sempretem que ter certas decisões quesetoma lá, tu tem quefazercumprir, então, às vezes, dáum pouquinho deraiva, masem seguidapassa. A gentesabe quetem certas coisas que, tem que ser cumpridas efeitas e que não adianta (D 22).

Outros depoentes expõem resistência e insubordinação, expressam que, quando algo é imposto e eles não concordam, não o fazem e encerram o assunto:

Quandotemumacoisaqueeunão concordo, eunão vou. Eu não gosto disso aqui, não tem nada a ver comigo, en fico indignada, eu digo:bom, comonão tinhamparaquem mandar derampramim(D1).

Consideramos também marcantes, neste estudo, que nas mudanças requeridas na prática dos enfermeiros gerentes, a incorporação dos avanços tecnológicos; e, na criação de novas demandas sociais, há influência dos fatores externos sobre a vida privada do ser humano trabalhador. Assim, é possível notar que aparece, de forma mais clara, uma crise nos modelos que primam pela dicotomia e fragmentação.

No entendimento dessas situações, torna-se fundamental investigar a valorização de outras dimensões

Texto Contexto Enferm, Florianópolis, 2006 Jul-Set; 15(3): 449-57. 
que fazem parte do vivido do enfermeiro gerente. Para tanto, é relevante refletir sobre o desempenho profissional, no que tange às inclusões de um conjunto complexo de hábitos cotidianos, ideologias e de suas representações no mundo do trabalho em Enfermagem, incluindo aí a subdivisão dos papéis conforme o gênero.

O ser enfermeiro gerente está vinculado a uma série de concepções e práticas inclusas em outros espaços (não só sociais, mas físicos) em que vigoram hábitos, prescrições, proibições, crenças que são seguidos no cotidiano. Isso envolve desde a influência do cargo sobre a forma de vestir-se até os preparativos e as prerrogativas de saída de casa para o trabalho, ou seja, o profissional não está isento de amalgamar seus rituais de sua vida privada, com os de sua vida pública, o inverso também é verdadeiro. As regras que gerem ambas não são as mesmas, ainda que variem conforme as diversas culturas. ${ }^{16}$

É pertinente salientar que a lógica de elaboração dos rituais segue uma ordem, a qual é interessante ser exposta e pensada sob a ótica da singularidade do homem, que não busca a individuação, mas a socialização. O ser humano é um sujeito social, cujas experiências, atividades e significados estão estreitamente ligados às estruturas sociais e a forma pela qual o indivíduo interage com os seus iquais em determinado contexto. ${ }^{17} \mathrm{Como}$ dado comprobatório dessa feita, apresentamos o seguinte fragmento de um de nossos depoimentos: [...] dá uma experiência, bastante de tudo e tu vêtodo o andar, a unidade, acho que isso ajuda bastante, maséestressante(D8).

Depreende-se que existe certo sofrimento gerado pelo trabalho, expresso por emoções como: angústia, cansaço, hipertensão, ausência de descanso, ansiedade e estresse, por assumir a função com total envolvimento. Os enfermeiros que compuseram o estudo manifestaram dificuldades em desligarem-se do hospital nas folgas, mostrando uma completa miscigenação, imersão do trabalho em suas vidas. Para eles isso é positivo, visto abrir horizontes, conduzir a melhores relações e criar estratégias para a vida. Com relação a isso, os depoentes esclarecem: penso que tu estás no papel de gerência, tu te sente eéo espelho, éa linha de frente. Então, isso às vezes modifica a tua maneira de viver a vida, atéas vezes tu leva para casa isso sem querer. Eu já tenho uma característica de querer tomar as decisoes, sou meio onipotente, atéprocuro me controlar, dai eu penso porque eu estou fazendo isso, eu tento não deixar que isso afete a minha saúde mental, tento evitarisso eme corrigir(D20).

Teminfluencia e bastante, no sentido de aumentar a responsabilidade. De deixar mais ligado. Na folga, tu dá uma passada ou liga(D11).

Como denotamos, há o desejo deles de sempre fazer mais, eles cobram de si mesmos as circunstâncias desfavoráveis, com isso há preocupação com exatidão, horários e com a perfeição. A esse respeito, alerta-se: "as vítimas ideais dos perversos morais são aqueles que, sentem-se obrigadas a fazer sempre mais, a esforçarem-se demais, para dar a qualquer preço uma melhor imagem de si mesmas. É, pois, a força vital das vítimas que as transforma em presas. Elas têm necessidade de dar e os perversos narcisistas de tomar: não se pode sonhar encontro mais ideal. Um recusa toda e qualquer culpa, o outro tem uma propensão natural a sentir-se culpado. Para que neste jogo não se acenda uma vela para um mal defunto, é necessário que a vítima esteja à altura, isto é, que saiba resistir em um primeiro momento, para acabar cedendo em seguida". ${ }^{15: 160-1}$

É importante pensar sobre a situação dos maridos ou esposas e familiares dos enfermeiros gerentes, quanto à questão do egocentrismo, pois cabe questionar: o cotidiano é uma manifestação extrema do etnocentrismo? O que se supõe que esse impulso influi nas demais atividades do dia-a-dia, pois extrapolam horários de trabalho, levam atividades para fazerem em casa, permanecem preocupados e com dificuldades de desligarem-se das questões de exercício de suas funções? Existe uma espécie de idolatria ao trabalho nos depoimentos dos entrevistados?

Interpretamos, portanto, que o desejo de ser reconhecido, gera diversificadas manifestações corpóreas e culturais no enfermeiro gerente e uma ilimitada dedicação às funções gerenciais, e (talvez) uma considerável profissionalização. Também, há uma recusa em dar-se conta do assédio da empresa (que finge não vê-lo) e das repercussões que ocorrem na vida do trabalhador que não percebe a interação assimétrica existente em seu local de trabalho.

\section{CONSIDERAÇÕES FINAIS}

Assentados no século XXI, acreditamos na necessidade de (re)pensar a ordem até hoje instituída, que embasa o comando. Para tanto, é necessário explorar as contradições ante a complexidade do ser humano e do exercício da gerência do enfermeiro, questões relativas ao fazer, ao saber, ao desejo, ao grupo, a fim de interpretá-las como forma de dar vazão à flexibilidade e investimento em um trabalho mais estimulante, na tentativa de amenizar as agruras do local de trabalho, reencontrando o outro sob um traba- 
lho de mediação que reconheça a violência perversa que se manifesta através do nosso corpo.

Os resultados alcançados mostram que as manifestações culturais e corpóreas no exercício da gerência do enfermeiro apareceram de forma objetiva e subjetiva sob diferentes formas e refletem a complexidade do tipo de produção, que envolve desde os meios materiais até as tecnologias e conhecimentos incorporados. Assim sendo, procuramos discernir e compreender os modos de ser e de atuar, a partir do discurso dos enfermeiros entrevistados e da observação de algumas de suas atividades.

Dessa forma, consideramos fundamental o reconhecer nossa cultura gerencial própria a fim de objetivarmos nossa práxis, e cuidar do devir. Portanto, é importante valorizar as singularidades e romper com o coletivo homogeneizado, de forma a encarar os pontos frágeis, diferenças ideológicas, divergências quanto aos encaminhamentos e valorização ética, através de uma prática reflexiva diária e integrativa.

\section{REFERÊNCIAS}

1 Prochnow AG. O exercício da gerencial do enfermeiro: cultura e perspectivas interpretativas [tese]. Rio de Janeiro (RJ): UFRJ/Programa de Pós-Graduação em Enfermagem; 2004.

2 TrevizanMA. Aspectoséticos na ação gerencial do enfermeiro. Rev Latino-American. Enferm. 2002 Jan-Fev; 10 (1): 85-9.

3 Geertz C. A interpretação das culturas. Rio de Janeiro (RJ): Zahar; 1973.

4 Geertz C. A interpretação das culturas. Rio de Janeiro (RJ): Livros Técnicos e Científicos; 1989.

5 Geertz C. O saber local: novos ensaios em antropologia interpretativa. Petrópolis (RJ): Vozes; 1997.
6 Geertz C. Nova luz sobre a antropologia. Rio de Janeiro (RJ): Zahar; 2001.

7 Geertz C. Curriculum vitae [acesso em 2004 Jun 15]. Disponível em: http://www.sss.ias.edu/home/ geertz.html

8 Laplantine F. Aprender antropologia. São Paulo (SP): Brasiliense; 2000.

9 Pereira A, Erdmann AL. Pluralismo cotidiano do espaço organizacional do enfermeiro. Texto Contexto Enferm. 1996 Jul-Dez; 5 (2): 147-55.

10 Erdmann AL. Administração do processo de trabalho e da assistência de enfermagem. In: Santos I. Enfermagem fundamental. São Paulo (SP): Atheneu; 2001. p.143-55.

11 Ministério da Saúde (BR), Conselho Nacional de Saúde, Comitê Nacional de Etica sobre Pesquisa em Seres Humanos. Resolução No 196 de 10 de outubro de 1996: dispõe sobre diretrizes e normas regulamentadoras de pesquisa envolvendo seres humanos. Brasília (DF): $\mathrm{O}$ Conselho; 1996.

12 Ferreira J. O corpo sígnico. In: Alves PC, Minayo MCS. Saúde e doença: um olhar antropológico. Rio de Janeiro (RJ): FIOCRUZ; 1994. p.101-11.

13 Mondin B. O homem: quem é ele: elementos de antropologia filosófica. São Paulo (SP): Paulus; 1980.

14 Rabelo MCM. Religião, ritual e cura. In: Alves PC, Minayo MCS. Saúde e doença: um olhar antropológico. Rio de Janeiro (RJ): FIOCRUZ; 1994. p.47-56.

15 Hirigoyen M. Assédio moral: a violência perversa no cotidiano. 6a ed. Rio de Janeiro (RJ): Bertrand Brasil; 2003.

16 Todorov T. A vida em comum. Campinas (SP): Papirus; 1996.

17 Deslandes SF, Assis SG. Abordagens quantitativa e qualitativa em saúde: o diálogo das diferenças. In: Minayo MSC. Caminhos do pensamento: epistemologia e método. Rio de Janeiro (RJ): FIOCRUZ; 2002. p.195-223. 